\title{
Analyzing Second Language Written Summaries at University Level
}

\author{
Katarina Zamborova ${ }^{1}$, Blanka Klimova ${ }^{2 *}$ \\ ${ }^{1}$ Department of English language, Faculty of Applied Languages, The University of Economics in Bratislava, Dolnozemská cesta 1, \\ Bratislava 85235 Bratislava, Slovakia \\ ${ }^{2}$ Department of Applied Linguistics, Faculty of Informatics and Management, University of Hradec Kralove, Rokitanskeho 62, Hradec \\ Kralove 500 03, Czech Republic
}

\begin{abstract}
Objective: The objectives of the study are to identify and categorize non-native students' errors in the written summaries, to see which research instruments - the mobile reading app (experimental group) or internet-based article (control group) are more effective, and to determine if language proficiency of students will improve. Methods: This study uses an analysis of linguistic-stylistic errors as a research method on the written performance of 29 EFL Slovak students in 29 written summaries. Findings: The findings indicate that the most problematic areas in writing summaries were grammatical (determiners), followed by stylistic (text coherence, slang words, and punctuation), lexical (word collocations), and lexico-stylistic errors (prepositions). Overall, students' proficiency in both groups rose from $\mathrm{B} 2$ to $\mathrm{C} 1$ level by $38 \%$ of the students (11 students). Therefore, both methods - the reading app and internet-based articles are effective. Novelty: The novelty of the study consists in enriching the existing literature by pointing out errors of EFL Slovak students making in writing summaries by exploiting modern technology in the writing process.
\end{abstract}

\section{Keywords:}

EFL/ESL Writing;

Summaries; Technology;

EFL Students;

English; Slovak.

\section{Article History:}

Received: 22 June 2021

Revised: $\quad 25$ September 2021

Accepted: $\quad 09 \quad$ October 2021

Published: 01 December 2021

\section{1- Introduction}

One of the key requirements for English as a Second/Foreign Language (ESL/EFL) students, when they transfer from high school to higher education, is to produce formal texts. However, not all students are prepared for this change or trained to produce formal academic writing that differs from the informal writing students use daily in their social media communication. What is more, they do not practice this type of writing at secondary schools in their mother tongue or in a foreign language [1-4]. Scholars worldwide have investigated ESL/EFL writing and many books and studies have been published on the topic [5-7]. The problems with ESL/EFL writing result from the absence of using the conventions and features of academic writing [8-10]. The texts are perceived to be vague and confusing, rhetorically unstructured, and overly personal. There is an absence of hedging, modal verbs, pronouns, active and passive voice, balanced generalization, and even exemplification. Students, on the other hand, experience frustration and alienation because they think the faculty is unreasonably demanding and exclusive, and their own best efforts are under evaluated and/or unrecognized [5]. Students need to learn how to approach new information and develop their knowledge in their writing courses. Most importantly, register is understood as a range of linguistic aspects related to the context in which authors write. Register includes formality, elaborate sentence structure, specialist terminology, and the avoidance of personal voice. Formality is depicted in the use of technical, elevated, or abstract vocabulary, complex sentence structures, and the avoidance of the personal voice (I, you). Many ideas are packed into fewer words, primarily through a greater variety of lexical items or vocabulary [11]. Typical features of academic register are:

\footnotetext{
*CONTACT: blanka.klimova@uhk.cz
}

DOI: http://dx.doi.org/10.28991/esj-2021-01322

(C) 2021 by the authors. Licensee ESJ, Italy. This is an open access article under the terms and conditions of the Creative Commons Attribution (CC-BY) license (https://creativecommons.org/licenses/by/4.0/). 
- High lexical density: a large number of vocabulary items, other than verbs, per clause;

- Highly nominal style: greater use of nouns than verbs;

- Impersonal construction: subjects or agents of clauses are often put to the background;

- Hedging and emphasizing: verbs and phrases are used to modify statements made [11].

As evoked, formal writing distinguishes from informal in several key facts as depicted in the following Table 1:

Table 1. Difference between formal and informal language (Adapted from [12]).

\begin{tabular}{ccc}
\hline Domain & Informal language & Formal language \\
\hline $\begin{array}{c}\text { Contracted and full verb forms } \\
\text { Colloquial and more formal } \\
\text { expressions }\end{array}$ & I'm, she's, they can't & She is, they cannot \\
Non-standard or standard forms & She slagged him off & In a derogatory way \\
Everyday' or subject-specific terms & She were, they was & Chas, they were
\end{tabular}

The use or not of the first-person ' $\mathrm{I}^{\prime}$

I think there are three main reasons why it is important to explore the value of talk in learning
There are three main reasons why it is important to explore the value of talk in learning

To summarize, formal writing provides factual and precise information that must be clear, concise, unambiguous, and explicit with no space for redundancies, repetition, or unimportant information. The tone should be formal, impersonal, and objective with the use of standard language. The third person prevails, and the only place where the author's opinion is heard is in the conclusion [4]. It is considered to be ideal, however, not very often obtained. It is necessary to train students in that way, especially in Humanities, however, taking a stance is legitimate because students encounter opinions of authors throughout their paper.

Formality is a feature of a summary writing which students are asked to produce in higher educational institutions. The pre-condition for a good quality summary is to both demonstrate reading and writing abilities [13]. Moreover, the process requires one to read closely and imply a mental process to eliminate irrelevant ideas and keep it to the text's theme. Students also improve their former writing rules and grammar [9]. In general, summaries are short statements that condense information and reflect the gist of the discourse [14]. When writing a summary, some textual actions are fulfilled, such as defining/forming the main idea, defining/forming the sub-ideas connected to the main idea, erasing the redundant and trivial sentences, and generalizing or restructuring some sentences. Hence, the act of creating a summary requires taking a text as the source text and transforming it into a new text from the background information they have [15]. Furthermore, summaries are based on constructing a general conceptual framework from analysis of the passage and synthesis of specific information from it.

Subsequently, this article presents research of written summaries in the literature review section, which is then followed by the introduction of the study with analysis and categorization of linguistic-stylistic errors. Then it moves to discussion and conclusion of this research.

\section{2- Literature Review}

Writing summaries is considered to be a complex process, and based on authors' experience, university students face difficulties writing them. Furthermore, many teachers expect students to be able to write them prior to instruction. It has been researched that summaries strengthen comprehension, memory, recall, and vocabulary [14]. Research suggests that secondary school students lack the cognitive and metacognitive processes that would enable them to make strategic use of reading and writing, and therefore, there is an urgent need for work on tasks of this kind in the classroom [16]. The 2010 study [14] found that students in primary, secondary, and higher education did not have adequate skills for writing proper headings and main and sub-ideas, as well as face problems with generalization and restructuring the original text. Girls and higher education students were more successful, however, not adequate. Nevertheless, the study claims that with aging summarization skills develop. General results show that students seem to lack knowledge of and skills for what to do [14]. Consequently, innovative approaches have arisen through collaborative writing approaches for writing summaries. Analysis of the data suggests a positive perception of the collaborative procedure, specifically for enhancing students' writing and language proficiency [17].

More recently, other innovative instructional techniques have been used to enhance students' summary writing ability [18]. Specifically, the effects of automatic scaffolding and measurement of three-layer concept maps (1. the central idea of the title, 2. the main idea of each paragraph, and 3. the supporting ideas in each paragraph) were used by university students in writing summaries. The findings indicate that the experimental group made more significant improvements in reading comprehension and summary writing than those in the control group [18]. Additionally, another study probed two instructional techniques, Network Tree Advance Organizers (NTAO) and Marginal Glosses 
(MG5), to study 60 EFL learners's summary writing ability. They divided the students into two experimental groups (one using NTAO and the other MG5) and one control group that followed a traditional writing class. The findings suggest NTAO outperformed the other two techniques and paved the way for more elaborate and detailed information processing and prompted language learners to prioritize, organize, and classify information [19]. Interestingly, when researching summaries, one also needs to take L2 lexical proficiency into consideration (structure of semantic network of words, and the ability to manipulate words metalinguistically) [20].

Therefore, this study tries to reflect on existing findings from the literature review and help students to improve their writing skills, particularly when writing formal summaries. As mentioned in the Introduction, students lack this skill, which is necessary for enhancing their information processing and thus, logical thinking. In this respect, the findings of this article are important. In addition, the article enriches the previous findings with the authors' intention to reveal how this skill can be taught and practiced with the use of technologies employed in developing students' skills in the writing process, such as reading skills and acquisition of second language vocabulary. The objectives of this study is to identify and categorize non-native students' errors in the written summaries, to see which research instruments - the mobile reading app (experimental group) or internet-based article (control group) are more effective, and if the language proficiency of students will improve.

\section{3- Materials and Methods}

The current pilot study includes a research sample of undergraduate students from the University of Economics in Bratislava, Slovakia, specifically from three different faculties - Business Management, Economic Informatics, and National Economy. All students were subjected to the placement TrackTest [21] to find their English proficiency prior to the study. Originally, 116 undergraduate students were tested. They were at different levels of English proficiency, ranging from level A2 to $\mathrm{C} 1$ of the Common European Framework of Reference (CEFR) [22]. Subsequently, only students with B2 level were selected for this for this experiment. Altogether, there were 30 students in both groups. One student dropped from the project, thus the final number was 29 students. They were divided into one experimental $(\mathrm{n}=14)$ and one control group $(\mathrm{n}=15)$. Their ages ranged from $19-23$ with the proportion of $\mathrm{M}=21 \%$ and $\mathrm{F}=79 \%$ in the experimental group, whereas in the control group $\mathrm{M}=0 \%$ and $\mathrm{F}=100 \%$. Students in the experimental group were asked to work with the research instruments - Blinkist, a mobile reading app. The app summarizes books into 15- minute reads/audios, and one can work with a free book in the app on a daily basis. The app is available in English and German, and the topics of the non-fiction books range from business to psychology, history and self-development. Provided a person buys the subscription for the app, he/she can enjoy more than 4,500 books [23]. The control group read the internet-based articles on current topics from renowned publishers as Harvard Business Review, Forbes, the Guardian, or the British Council. Both methods provide a student with digital reading materials, however, they differ in a way that mobile app reading has a smaller size - mobile screen (see Figures 1 and 2), and the reading material from the Internet can be read on a computer or is able to be printed out (see Figure 3 ). The length of the reading time including the vocabulary search for both methods was the same - approximately 20-25 minutes.

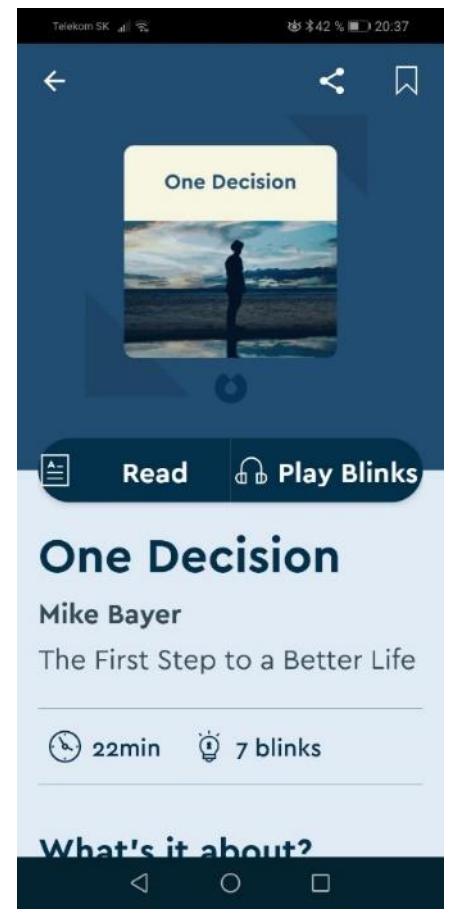

Figure 1. An illustration of the mobile app [23].

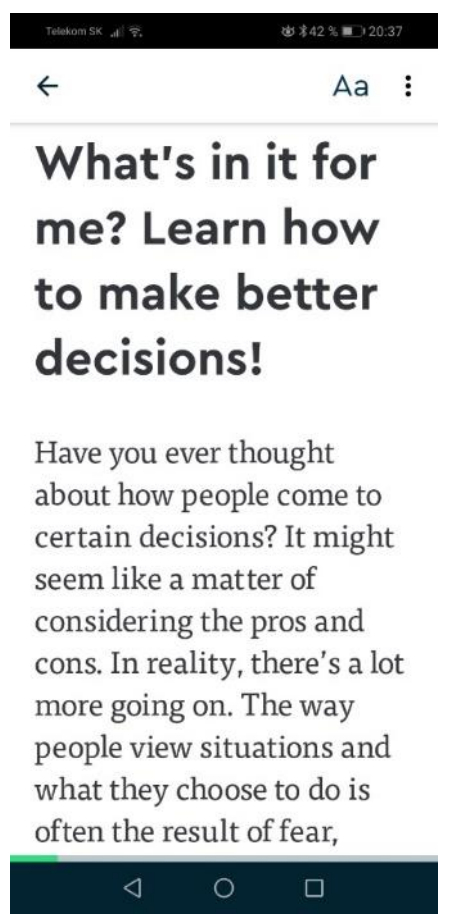

Figure 2. An illustration of the mobile app articles [24]. 


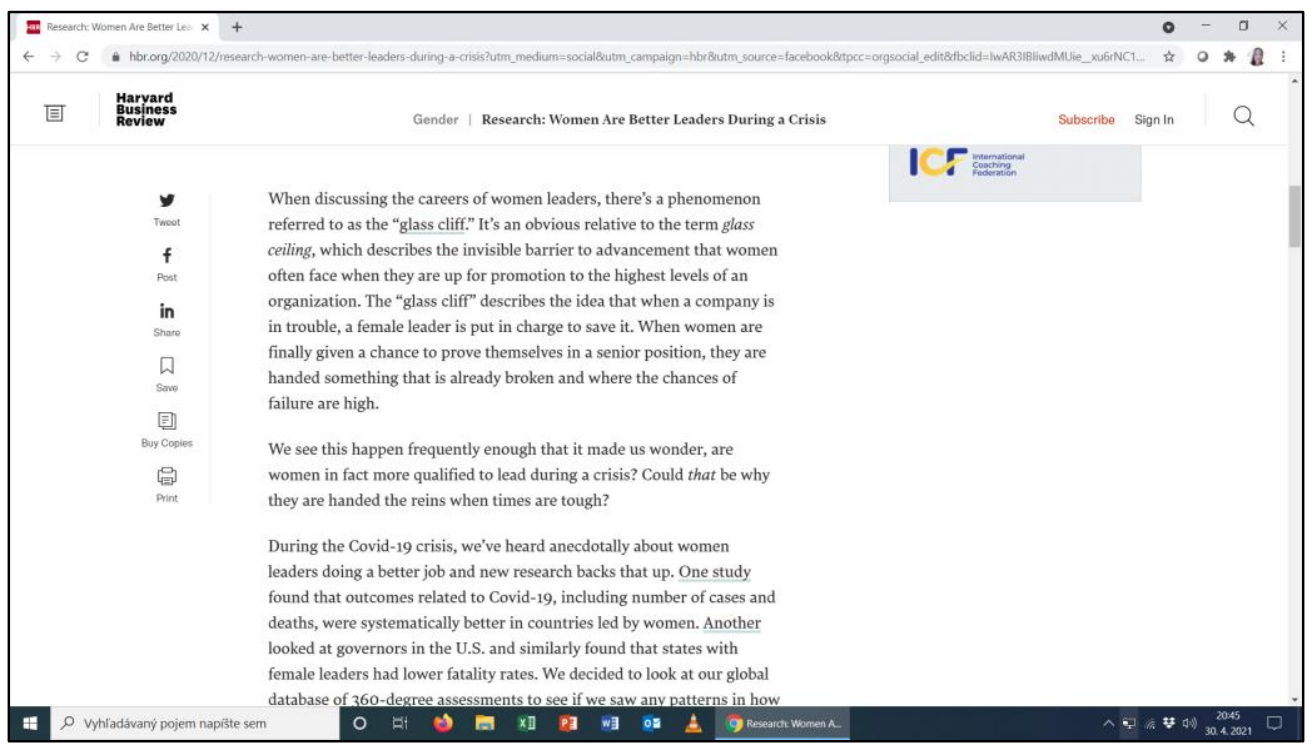

Figure 3. An illustration of the Internet-based articles [25].

Both groups were held accountable by sharing their reading experiences and highlights from the books/articles in the class every week during the semester. At the same time, both groups were instructed weekly on how to write a summary, which was the research material. In the so-called writing windows, the teacher covered related issues for writing a summary, such as fluency, content, formal style, voice, length, and conventions. Thus, one group was using the mobile app for reading the articles, while the control group exploited the Internet-based articles without using this mobile app. The students received specific recommendations before writing a summary. Each of the summaries was proofread with further recommendations for its improvement. The students also received specific recommendations to concentrate on when writing a final summary. The experiment lasted 10 weeks. The research method included linguisticstylistic analysis of the errors in the given summaries. The research investigated whether there was improvement in the students' level of proficiency at the end of the experiment.

In the scope of this article, we analyzed 29 summaries based on the books and articles the students read and chose to write about. Each summary was 150-200 words. The sample is not large, but we draw attention to specific language difficulties the Slovak EFL students faced in writing their summaries in formal English. Thus, this analysis reveals the most common errors Slovak EFL students make. This article focuses particularly on the linguistic-stylistic aspects of the language (lexis, grammar, text coherence, and conventions). Figure 4 demonstrates the whole research methodology.

\begin{tabular}{|c|c|c|c|c|}
\hline Stage 1 & Stage 2 & Stage 3 & Stage 4 & Stage 5 \\
\hline $\begin{array}{l}\text {-Planning } \\
\text { research and } \\
\text { preparation, } \\
\text { stating } \\
\text { objective }\end{array}$ & $\begin{array}{l}\text { - Literature } \\
\text { research }\end{array}$ & $\begin{array}{l}\text {-Choosing the } \\
\text { research } \\
\text { sample }\end{array}$ & $\begin{array}{l}\text {-Data collection } \\
\text {-Data analysis } \\
\text { and their } \\
\text { description }\end{array}$ & $\begin{array}{l}\text {-Interpretation } \\
\text { of the results }\end{array}$ \\
\hline
\end{tabular}

Figure 4. Research methodology.

\section{3-1-Analysis of the Summaries}

The following Table 2 depicts four major error types in the students' summaries (experimental and control groups) [4]. The results in Table 2 suggest that there were no clear differences between both groups in making errors when writing a summary. The most problematic area for both groups was grammar, specifically determiners where the control group reached a higher percentage of errors (28.5\%) than the experimental group (17.4\%). However, in verb forms, both groups reached the same amount of errors. Interestingly, the experimental group indicated more errors with the genitive of form $(4.9 \%)$ than the control group $(2.1 \%)$. The same applies to stylistic errors - text coherence where the experimental group did a slightly better job (10.3\%) than the control group (14.5\%). Both groups used slang in their summaries and showed similar problems with punctuation. The same was true for the improper usage of pronouns (we, us, our, your, you), constructed forms, and spelling. On the other hand, when it came to lexical errors, the experimental group had more errors $(9.8 \%)$ than the control group (4.7\%). However, the error differences between both groups are not striking. Therefore, the study may not propose some generalizations about students' performance based on differences in methods. 
Table 2. Distribution of four major error types in summaries.

\begin{tabular}{|c|c|c|}
\hline & Experimental Group & Control Group \\
\hline \multicolumn{3}{|l|}{ Lexical errors } \\
\hline Word collocations & $18(9.8 \%)$ & $9(4.7 \%)$ \\
\hline \multicolumn{3}{|l|}{ Lexico-grammatical errors } \\
\hline Prepositions & $13(7 \%)$ & $6(3.1 \%)$ \\
\hline \multicolumn{3}{|l|}{ Grammatical errors } \\
\hline Determiners & $32(17.4 \%)$ & $55(28.5 \%)$ \\
\hline Genitive of & $9(4.9 \%)$ & $2(1 \%)$ \\
\hline Verb forms & $11(6 \%)$ & $12(6.2 \%)$ \\
\hline Word order & $2(1.1 \%)$ & $4(2.1 \%)$ \\
\hline Others & $9(4.9 \%)$ & $10(5.2 \%)$ \\
\hline \multicolumn{3}{|l|}{ Stylistic errors } \\
\hline Text coherence & $19(10.3 \%)$ & $28(14.5 \%)$ \\
\hline Slang & $24(13 \%)$ & $21(10.9 \%)$ \\
\hline Punctuation & $15(8.2 \%)$ & $20(10.4 \%)$ \\
\hline Improper usage of pronouns (we, us, our, your, you) & $13(7.1 \%)$ & $11(5.7 \%)$ \\
\hline Constructed forms & $10(5.4 \%)$ & $9(4.7 \%)$ \\
\hline Spelling & $9(4.9 \%)$ & $6(3 \%)$ \\
\hline TOTAL & $184(100 \%)$ & $193(100 \%)$ \\
\hline
\end{tabular}

As it has been mentioned, the most identified common error in both groups was grammar: using determiners. There are no determiners in the Slovak language, therefore, it is considered the most problematic grammar issue to acquire and teach. In the control group, errors with definite articles prevailed as anaphoric reference (1); in noun phrases with post modification as cataphoric reference (2); using indefinite article instead of the definite one (3); and incorrect usage with names (4); abstract nouns (5); and numbers (6).

1. ...they attend exhibition of paintings $>$ they attend the exhibition of paintings

The book chronicles whole life of ... > The book chronicles the whole life of...

2. Helpful manual teaches us.... > The helpful manual teaches us

Life-affirming energy of God lies in ... > The life-affirming energy of God lies in...

3. The main idea of this self-help book is an importance of... > The main idea of this self-help book is the importance of ...

4. When the Prince Charming holds a ball... > When Prince Charming holds a ball...

5. ...earned the fame $>$...earned fame

6. ....authors of 20th century > authors of the 20th century

second famous book $>$ the second famous book

The students lacked indefinite articles when describing a singular countable thing for the first time (7); referred to the profession (8); described a person (9); and/or omitted them (10).

7. "My life and work" is autobiography... > "My life and work" is an autobiography...

8. He was founder of ... > He was a founder of ...

9. ...such brave, kind and beautiful person... >...such a brave, kind and beautiful person

10. to escape from locked room > to escape from a locked room

Also, the experimental group of students made errors with the genitive of form (11-13).

11. The book chronicles the whole life one of the greatest American ... > The book chronicles the whole life of one of the greatest American...

12. There are useful types how to get through anything > There are useful types of how to get through anything

13. business must be a way doing service > business must be a way of doing service

In addition, the students mixed up like and as. The Slovak language has only one expression for this (14). 
14. work like a slave >work as a slave; you can imagine it like something balanced> you can imagine it as something balanced; he was there like a reporter > as a reporter

In lexico-grammatical errors, there were problems with prepositions because of the Slovak language interference $(15)$.

15. affordable by public people $>$ for; written well to every person $>$ for; interests about $>$ in; shocked $a t>$ shocked by/about; meet with strange people > meet strange people

Errors in verb forms were identified mainly in tenses, such as incorrect forms of past tense and with contracted forms of auxiliary verbs (16); missing -s ending in present simple tense (17); incorrect passive form (18); and missing -ing form of verbs (19).

16. His father didn't supported him > His father did not support him

17. Roderic want to wish > Roderic wants to wish

18. Darcy's snobbish behavior is clarifies > Darcy's snobbish behavior is clarified

She was declared drowned $>$ She was declared to be drowned

19. ...each of them has a different purpose deals with a different pain, heals different headache > ..each of them has a different purpose dealing with different pain and healing different headache

Students experience problems with the passive voice, as there is a lack of practicing it in real life situations. Generally, Slovak language tends to use the active voice more often. Moreover, the students only used present or past tenses in their summaries. Occasionally, there was present perfect and passive. The students did not feel confident using other tenses, since in Slovak there are just three tenses - present, past, and future. In addition, in some cases, the students did not keep the tense sequence and mixed present and past tenses in the paragraph instead of keeping the same tense.

Stylistic errors were the second biggest problem, specifically text coherence. Despite an explanation by the teacher, the students rarely joined the introduction, body, and conclusion of the summary through linking words. They were given material about linking words; however, they did not apply them in their writing. It was very common that students started the sentence with but, because, so and also, which is not recommended in a formal style. There were also occurrences of literally translating slang expressions (to put it another way; And of course; and that is why), using slang phrasal verbs (to move on; to figure out; give up; hanging around the house; stand out; turn out; go on) or shortening sentences (When young, he ...).

Furthermore, the students did not develop an introduction and conclusion, despite lectures in which the teacher answered questions about the process. Interestingly, the students developed the body of the summary strongly when it came to the description of the plot. The students were influenced by their mother tongue. Slovak linguistics do not put commas when enumerating more than two nouns or activities $(20,21)$; capital letters (22); quotation marks influenced by the Slovak language (23); contracted forms of verbs (24), and errors in not writing numerals up to ten in word forms (25).

20. Luisa finds her beautiful, elegant and sweet > Luisa finds her beautiful, elegant, and sweet

21. ...she usually read books, watched serials and went to a support group > ...she usually read books, watched serials, and went to a support group

22. ...the best french authors > the best French authors

23. "I won't describe what I look like...". > "I will not describe what I look like..."

24. shouldn't, don't, didn't, it's > should not, do not, did not, it is

25. $2,3>$ two, three

Improper use of personal pronouns for addressing the audience instead of the neutral tone or third person singular were similar for the experimental group by $5.4 \%$ and in control group $4.7 \%$. Moreover, spelling mistakes comprise of $4.9 \%$ in experimental and $3 \%$ in control group. It is interesting to look at the lexical errors, which represent $9.8 \%$ in the experimental and $4.7 \%$ in the control group. Some of them includes incorrect word collocations (26); interference of Slovak language (27-30); abundance of the word phrase (31); occurrence of false friends/faux amis (32):

26. overcome cancer > beat cancer

27. the book named $>$ the book called

28. the overall book $>$ the whole book

29. study proceed in Germany $>$ a study performed in Germany

30. the book is about/talks about $>$ the book describes/focuses on

31. public people $>$ public

32. types $>$ tips 
The findings after the experiment were the following: there were $38 \%$ of students $(n=11)$ from both groups whose language proficiency rose from B2 to $\mathrm{C} 1$ level. It is considered to be successful as this improvement happened only after 10 weeks of intensive reading and read-to-write tasks. It can be concluded that it was specifically ten females and one male who improved their proficiency. As in both groups, female gender prevailed (control group: $\mathrm{F}=100 \%, \mathrm{M}=0 \%$; experimental group: $\mathrm{F}=79 \%, \mathrm{M}=21 \%$ ). However, the study did not investigate the results of the gender differences in more details, as there is a lack of male representation.

\section{4- Results and Discussion}

Summary writing is a significant communication skill and has great importance in students' academic success. However, EFL students find it difficult and intimidating since it requires a confident knowledge of writing conventions, linguistics, grammar, and vocabulary in addition to developed thinking skills to express themselves proficiently in another language. Summary writing in a second language is a demanding cognitive activity in which teachers play a prominent role by providing feedback [7]. The results of the study on writing summaries by EFL Slovak learners is valuable for read-to-write research, which has been growing as a model [26]. Recently, there have been tendencies to modernize writing through a multifaceted academic writing module [6] as well as to develop summaries in the form of graphical abstracts, video abstracts, and plain language summaries. Research shows that the latter are perceived to be more effective ( $p<0.0025$ ) [8]. Interestingly, Algerian students with a different language background than Slovaks also experienced problems in tense verb agreement, article misuse, irregular verb past tense in addition to mechanics and style problems [9]. This is also true for the Czech university students [4].

Based on the results, there was no obvious difference between the experimental and control group. However, each group had weaknesses, although in different areas. While the control group had $28.5 \%$ errors in grammar (determiners), the experimental had 17. 4\%. In addition, in the stylistic area (text coherence), the control group scored $14.5 \%$, while the experimental group scored $10.3 \%$. Both groups used slang words - experimental $13 \%$ and control $10.9 \%$. On the other hand, when it came to lexical errors, the control group had a better performance, with $4.7 \%$, and the experimental group and 9.8\% errors. When it comes to their English proficiency, all students took the TrackTest [21] placement test again at the end of the experiment. The findings revealed that students' proficiency in both groups had risen from B2 to C1 level by $38 \%$ (11 students). Therefore, it can be concluded that both methods - the reading app and internet-based articles are effective methods when working on read-to-write tasks.

Similar findings concerning the students' academic performance were detected by Khazaal [27] whose results showed that there was a statistically significant difference in the postgraduates' performance before and after implementing the summarizing strategy. However, using the reading text can also improve students' reading comprehension skills and expand their vocabulary in a foreign language [28]. In addition, they are more engaged in learning by using digital media that they were used to when reading these texts [29]. There are several reasons for the weaknesses in the students' ${ }^{\prime}$ writing skills. The first is due to the teacher-centered approach that emphasizes correcting and directing the topics for writing. The second is the focus on the product of writing without considering the process. Some other reasons are the large size of the writing class and the disintegration of print culture and technologies [7].

Despite the limited time for teaching writing in our classes, this study worked with a small group (B2 students) in which each of the students received individual feedback as well could choose which book or article they summarized. Additionally, attention was paid to the so-called "regular writing windows" with general recommendations based on errors for improvement of their summaries. As emphasized, students must have a solid foundation of the grammatical and syntactical features of complex text to write at a college-level [9]. Thus, the first recommendation is to support students in using both mobile reading and internet-based articles for current experiences with the English language and noting the use of constructs like determiners in the given text. As mentioned, the Slovak language lacks determiners; therefore, students have trouble using them properly. Furthermore, intentional classes purely concentrating on the explanation of their usage might be a benefit. Students also need to be instructed in text coherence, especially by providing them explanations of linking words. They are especially important for connecting ideas throughout the summary. In addition, as an abundance of slang words and constructed forms were spotted in the summaries, students should be exposed to formal writings. Digital native students use social media extensively and are influenced by informal language, so attention needs to be drawn to technical writings related to their studies. Furthermore, the English - Slovak comparison of common preposition errors would seem like a plus for students. Unfortunately, the problem with prepositional phrases is that they should be learned by heart because most of the time, there is no logical reasoning because one cannot translate the phrases literally. It is suggested that students shall be introduced to corpus linguistic to discover characteristic language features of their discipline-specific corpora. It also underlined consciousness-raising techniques in translation from their mother tongue into English and the use of monolingual and collocation dictionaries. By this, they may realize language structures and patterns they still have not proceeded with when writing in English [4]. Most importantly, students should get an opportunity to work on the summaries each semester, as they need them in other content-related subject papers during their studies. The most important suggestion based on the study is to provide students with the experience of writing summaries from the first years of their studies bearing in mind there is 
no emphasis on writing them according to the secondary school curriculum since teachers can only develop summarizing skills in students by systematically training them to use these skills [30]. Therefore a proper approach to teaching summary writing skills should be employed [31]. Further research can concentrate on a longitudinal study with a bigger sample and a comparison of the features of the errors in other Slavic languages.

\section{5- Conclusion}

University students are already expected to write formal summaries at a high level prior to their first year of their studies. However, the reality is different because of the lack of attention to training this concept in high school English classes. Students might have higher motivation by using innovative research instruments such as mobile reading apps and internet-based articles and better transform to read-to-write tasks in a form of formal summaries. The study identified and categorized non-native Slovak students' errors in their written summaries where the findings indicated that the most problematic areas in writing summaries were grammatical (determiners), followed by stylistic (text coherence, slang words, and punctuation), lexical (word collocations), and lexico-stylistic errors (prepositions). Consequently, students' proficiency in both groups rose from B2 to $\mathrm{C} 1$ level by $38 \%$ (11 students). Therefore, both research instruments - the reading app and internet-based articles are effective. Based on the findings, the study recommends several strategies for EFL writing summaries such as including both mobile reading and internet-based articles into classes and detecting the use of constructs like determiners in the given text. Later, intentional classes purely concentrating on the explanation of their usage as well as analyzing text coherence (linking words) in a given text. To avoid slang and collocation in their writing, attention needs to be drawn to technical writing in their studies. Corpus linguistic, the use of monolingual and collocation dictionaries might be beneficial for students. Most importantly, students should be exposed to working on and writing summaries from their first year and alert high school teachers to introduce summaries to them gradually so students have smoother transition to the higher demands of university requirements in EFL classes.

\section{6- Declarations}

\section{6-1-Author Contributions}

Conceptualization, K.Z. and B.K.; methodology, K.Z., B.K.; software, Not applicable; validation, B.K.; formal analysis, K.Z. and B.K.; investigation, K.Z. and B.K.; resources, K.Z. and B.K.; data curation, K.Z.; writing-original Draft Preparation, K.Z. and B.K.; writing-review \& editing, K.Z., B.K.; visualization, K.Z.; supervision, B.K. All authors have read and agreed to the published version of the manuscript.

\section{6-2-Data Availability Statement}

Data available on request due to privacy restrictions: The data presented in this study are available on request from the corresponding author. The data are not publicly available due to the GDPR policy.

\section{6-3- Funding}

The authors received no financial support for the research, authorship, and/or publication of this article.

\section{6-4-Acknowledgements}

This paper was supported by the research project SPEV 2021, run at the Faculty of Informatics and Management, University of Hradec Kralove, Czech Republic. The authors thank Lukáš Šanda for his help with data collection.

\section{6-5-Conflicts of Interest}

The authors declare that there is no conflict of interests regarding the publication of this manuscript. In addition, the ethical issues, including plagiarism, informed consent, misconduct, data fabrication and/or falsification, double publication and/or submission, and redundancies have been completely observed by the authors.

\section{7- References}

[1] Perkins, Chris. "Sensitizing Advanced Learners to Problems of L1-L2 Translation." In Translation in Foreign Language Teaching and Testing, edited by Ch Titford and A Hieke, 51-72. Narr: Tübingen, (1985).

[2] Chamonikolasová, Jana, and Jaroslava Stašková. "Some Difficulties Facing Native Speakers of Czech and Slovak in Writing in English." In Theory and Practice in English Studies: Proceedings from the Eighth Conference of English, American and Canadian Studies (Linguistics, Methodology and Translation), 53-59. Brno, Czech Republic: Masaryk University, (2005).

[3] Frydrychová Klímová, B. Teaching Formal Written English. Gaudeamus: Hradec Kralove, (2012). 
[4] Frydrychová Klímová, B. “Common Mistakes in Scientific Prose-Style Writing”. From Theory to Practice 2014. Proceedings of the Sixth International Conference on Anglophone Studies, September 4-5, (2014): 69-76. Zlín, UTB.

[5] Hinkel, Eli. Teaching Academic ESL Writing: Practical Techniques in Vocabulary and Grammar. Teaching Academic ESL Writing: Practical Techniques in Vocabulary and Grammar. Lawrence Erlbaum Associates, Inc.: Mahwah, 2003. doi:10.4324/9781410609427.

[6] Marulanda, Niora Lucía, and Juan Martínez García. “Improving English Language Learners’ Academic Writing: A Multi-Strategy Approach to a Multi-Dimensional Challenge.” Gist Education and Learning Research Journal 14, no. 14 (2017): 49-67.

[7] Javadi-Safa, Azim. “A Brief Overview of Key Issues in Second Language Writing Teaching and Research.” International Journal of Education and Literacy Studies 6, no. 2 (2018): 12. doi:10.7575/aiac.ijels.v.6n.2p.15.

[8] Bredbenner, Kate, and Sanford M. Simon. "Video Abstracts and Plain Language Summaries Are More Effective than Graphical Abstracts and Published Abstracts.” PLoS ONE 14, no. 11 (2019): 1-19. doi:10.1371/journal.pone.0224697.

[9] Mouri, Chahrazede. "Summarizing as a Strategy to Enhance Grammar and Writing Skills: The Case of First Year LMD Learners at the Algerian University Dr. Tahar Moulay-Saida." Arab World English Journal 11, no. 2 (2020): 303-10. doi:10.24093/awej/vol11no2.21.

[10] Rothwell, Edward J., and Michael J. Cloud. "Engineering Writing by Design: Creating Formal Documents of Lasting Value" Boca Raton, FL, USA: Second Edition”. Taylor and Francis: Boca Raton, FL, USA, (2020).

[11] Harris, J. "Teaching Academic Writing a Toolkit for Higher Education.” Edited by C Coffin. Teaching Academic Writing. London and New York, England and USA, (2003).

[12] Lillis, Theresa M., and Joan Swann. "Giving Feedback on Student Writing.” In Teaching Academic Writing: A Toolkit for Higher Education, edited by C Coffin, 101-29. London and New York, England and USA, 2003.

[13] Li, Jiuliang. "The Role of Reading and Writing in Summarization as an Integrated Task." Language Testing in Asia 4, no. 1 (2014). doi:10.1186/2229-0443-4-3.

[14] Hill, Margaret. "Writing Summaries Promotes Thinking and Learning across the Curriculum: But Why Are They so Difficult to Write?” Journal of Reading 34, no. 7 (1991): 536-39.

[15] Choy, Siew Chee, and Mun Yee Lee. "Effects of Teaching Paraphrasing Skills to Students Learning Summary Writing in ESL." Journal of Teaching and Learning 8, no. 2 (2012): 77-89. doi:10.22329/jtl.v8i2.3145.

[16] Mateos, Mar, Elena Martín, Ruth Villalón, and María Luna. "Reading and Writing to Learn in Secondary Education: Online Processing Activity and Written Products in Summarizing and Synthesizing Tasks.” Reading and Writing 21, no. 7 (2008): 67597. doi:10.1007/s11145-007-9086-6.

[17] Lin, Ong Poh, and Nooreiny Maarof. "Collaborative Writing in Summary Writing: Student Perceptions and Problems.” Procedia - Social and Behavioral Sciences 90 (2013): 599-606. doi:10.1016/j.sbspro.2013.07.131.

[18] Yang, Yu Fen. "Automatic Scaffolding and Measurement of Concept Mapping for EFL Students to Write Summaries." Educational Technology and Society 18, no. 4 (2015): 273-86.

[19] Nevisi, Reza Bagheri, Rasoul Mohammad Hosseinpur, and Rahman Kolahkaj. "The Impact of Marginal Glosses and Network Tree Advance Organizers on Efl Learners' Summary Writing Ability.” Journal of Asia TEFL 16, no. 4 (2019): $1168-81$. doi:10.18823/asiatefl.2019.16.4.7.1168.

[20] Baba, Kyoko. “Aspects of Lexical Proficiency in Writing Summaries in a Foreign Language.” Journal of Second Language Writing 18, no. 3 (2009): 191-208. doi:10.1016/j.jslw.2009.05.003.

[21] TrackTest. Available online: https://tracktest.eu/ (accessed on April, 2021).

[22] Common European Framework of Reference for Languages (CEFR). Available online: https://www.coe.int/en/web/commoneuropean-framework-reference-languages (accessed on April 2021).

[23] Blinkist. Available online: https://www.blinkist.com/ (accessed on April 2021).

[24] Blinkist. Available online: https://www.blinkist.com/en/books/one-decision-en (accessed on April 2021).

[25] Zenger, Jack. and Folkman, Joseph. "Research: Women Are Better Leaders during a Crisis", (2020). Available online: https://hbr.org/ (accessed on April 2021).

[26] Li, Jiuliang. "Modeling the Process of Summary Writing of Chinese Learners of English as a Foreign Language." Irish Educational Studies 35, no. 1 (2016): 73-100. doi:10.1080/03323315.2016.1146154.

[27] Numan Khazaal, Edhah. “Improving Postgraduates' Academic Writing Skills with Summarizing Strategy.” Arab World English Journal 10, no. 3 (2019): 413-28. doi:10.24093/awej/vol10no3.29. 
[28] Girshin, T. "Students' Use of Summary in a Writing about Writing Class.” Open Access Library Journal, Vol. 5, No. 11, e464, (2018):1-20. doi:10.4236/oalib.1104648.

[29] Klimova, Blanka, and Marcel Pikhart. "Cognitive and Applied Linguistics Aspects of Using Social Media: The Impact of the Use of Facebook on Developing Writing Skills in Learning English as a Foreign Language.” European Journal of Investigation in Health, Psychology and Education 10, no. 1 (2020): 110-18. doi:10.3390/ejihpe10010010.

[30] Pečjak, Sonja, and Tina Pirc. "Developing Summarizing Skills in 4th Grade Students: Intervention Programme Effects." International Electronic Journal of Elementary Education 10, no. 5 (2018): 571-81. doi:10.26822/iejee.2018541306.

[31] Abeysena, Hashini. "Improving Basic Composition Skills of Secondary Level Students in the Sri the Lankan School Context: An Action Research." Literacy Information and Computer Education Journal 10, no. 1 (2019): 3119-27. doi:10.20533/licej.2040.2589.2019.0409. 